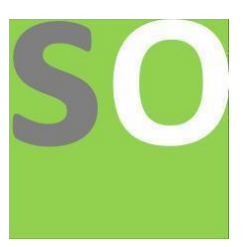

Article title: Known Human Carcinogens and the Importance of Toxicology in Cancer Research

Authors: Domina Petric[1]

Affiliations: Clinical pharmacology and toxicology, University Hospital Center, Soltanska 1, 21000 Split, Croatia[1]

Orcid ids: 0000-0001-5609-1675[1]

Contact e-mail: domina.petric@gmail.com

License information: This work has been published open access under Creative Commons Attribution License $\mathrm{http}: / / c r e a t i v e c o m m o n s . o r g / l i c e n s e s / b y / 4.0 /$, which permits unrestricted use, distribution, and reproduction in any medium, provided the original work is properly cited. Conditions, terms of use and publishing policy can be found at https://www.scienceopen.com/.

Preprint statement: This article is a preprint and has not been peer-reviewed, under consideration and submitted to ScienceOpen Preprints for open peer review.

DOI: 10.14293/S2199-1006.1.SOR-.PP6SWAP.v1

Preprint first posted online: 17 October 2021

Keywords: cancer, toxins, carcinogens, toxicology 


\title{
Known Human Carcinogens and the Importance of Toxicology in Cancer Research
}

Domina Petric, MD

\begin{abstract} cancer research, with toxicology playing a key role.

\section{INTRODUCTION}

The predominant view of cancer etiology is that the root cause lies at the genomic level, perhaps facilitated by exposure to radiation or toxic chemicals in the environment or diet ${ }^{1}$.
\end{abstract}

Aim of this article is to review the literature about known human carcinogens and emphasize the importance of toxicology in cancer research. Cancer etiology is multifactorial with toxins playing an important role, what accentuates the importance of multidisciplinary approach to

Known human carcinogens are:

- Aflatoxins

- Alcoholic beverage consumption

- 4-Aminobiphenyl

- Analgesic mixtures containing phenacetin

- Aristolochic acids

- Arsenic and inorganic arsenic compounds

- Asbestos

- Azathioprine
- Benzene

- Benzidine

- Beryllium and beryllium compounds

- Bis(chloromethyl) ether and technical-grade chloromethyl methyl ether

- 1,3-Butadiene

- 1,4-Butanediol dimethylsulfonate (also known as busulfan)

- Cadmium and cadmium compounds

- Chlorambucil

- 1-(2-Chloroethyl)-3-(4methylcyclohexyl)-1-nitrosourea (MeCCNU)

- Chromium hexavalent compounds - Coal tar pitches 
- Coal tars

- Coke oven emissions

- Cyclophosphamide

- Cyclosporin A

- Diethylstilbestrol (DES)

- Dyes metabolized to benzidine

- Epstein-Barr virus (EBV)

- Erionite

- Estrogens, steroidal

- Ethylene oxide

- Formaldehyde

- Helicobacter pylori

- Hepatitis B virus

- Hepatitis C virus

- Human immunodeficiency virus type $1(\mathrm{HIV}-1)$

- Human papilloma viruses (HPVs): some genital-mucosal types

- Human T-cell lymphotropic virus type 1 (HTLV-1)

- Kaposi sarcoma-associated herpesvirus (KSHV) (also known as human herpesvirus 8 , or HHV-8)

- Melphalan

- Merkel cell polyomavirus (MCV)
- Methoxsalen with ultraviolet A therapy (PUVA)

- Mineral oils (untreated and mildly treated)

- Mustard gas

- 2-Naphthylamine

- Neutrons

- Nickel compounds

- Radon

- Silica, crystalline (respirable size)

- Solar radiation

- Soots

- Strong inorganic acid mists containing sulfuric acid

- Sunlamps or sunbeds, exposure to

- Tamoxifen

- 2,3,7,8-Tetrachlorodibenzo-pdioxin (TCDD); "dioxin"

- Thiotepa

- Thorium dioxide

- Tobacco smoke, environmental

- Tobacco, smokeless

- Tobacco smoking

- o-Toluidine

- Trichloroethylene (TCE) 
- Ultraviolet (UV) radiation, broad spectrum

- Vinyl chloride

- Wood dust

- X-radiation and gamma radiation ${ }^{2}$

\section{AFLATOXINS}

Aflatoxins are secondary metabolites produced by different strains of fungi, like Aspergillus flavus and A. parasiticus, widely found as contaminants in a great variety of crops-cereals, oilseeds, tree nuts and spices. When the ruminants eat feedstuffs containing Aflatoxin B1 (AFB1), this toxin is metabolized and Aflatoxin M1 (AFM1) is excreted in milk. International Agency for Research on Cancer (IARC) classified AFB1 and AFM1 as human carcinogens belonging to Group 1 and Group 2B, respectively, with the formation of DNA adducts ${ }^{3}$.

It is reported in the literature that the increased risk of liver cancer is correlated to AFB1 exposure. In fact, AFB1 was indicated in 2002 to belong to Group 1 of the carcinogens because it induces the formation of DNA adducts that contribute to liver cancer formation ${ }^{4}$.
When the workers are subjected to pulmonary AFB1 exposure due to grain dusts, they can develop lung cancer ${ }^{5}$.

In 1993, Harrison et al., suggested that human aflatoxin exposure could represent a risk to organs other than liver, even in developed countries. To prove this statement, the authors analyzed normal and tumor tissues from different organs (colon, rectum, breast, cervix and liver) to find AFB1-DNA adduct. Interestingly all the samples resulted positive and, in particular, the colorectal tumor tissue showed a higher content of adduct compared to normal tissues from the same patients ${ }^{6}$.

Koshiol and coworkers showed in the study that exposure to AFB1 is associated with gallbladder cancer ${ }^{7}$.

In 2013, a study was conducted to assess if aflatoxins contamination of wheat flour could be related to high-risk esophageal cancer in the Golestan region of Iran. Authors demonstrated that in samples collected in esophageal cancer high-risk areas there were higher levels of AFB1 compared to low-risk areas of the same region $^{8}$.

AFB1 exposure was associated also with gastric cancer development. A casecontrol study evidenced that AFB1 intake 
was higher in gastric cancer patients than in controls, and that genetic polymorphism of CYP1A2 (rs2470890), one of the enzymes that metabolize AFB1, showed a lower risk of gastric carcinogenesis ${ }^{9}$.

\section{ALCOHOL}

Moderate alcohol drinking is defined as up to one drink per day for women and up to two drinks per day for men. Heavy alcohol drinking is defined as having 4 or more drinks on any day or 8 or more drinks per week for women and 5 or more drinks on any day or 15 or more drinks per week for men. Binge drinking is defined as consuming 4 or more drinks for women and 5 or more drinks for men in one sitting, typically in about 2 hours ${ }^{10}$.

Moderate to heavy alcohol consumption is associated with higher risks of certain head and neck cancers. Moderate drinkers have 1.8-fold higher risks of oral cavity (excluding the lips) and pharynx cancers, and 1.4-fold higher risks of larynx cancers than non-drinkers, and heavy drinkers have 5-fold higher risks of oral cavity and pharynx cancers and 2.6-fold higher risks of larynx cancers. Alcohol consumption at any level is associated with an increased risk of developing esophageal squamous cell carcinoma ${ }^{11,12}$.
Heavy alcohol consumption is associated with approximately 2 -fold increased risks of hepatocellular carcinoma and intrahepatic cholangiocarcinoma ${ }^{11-14}$.

Epidemiologic studies have consistently found an increased risk of breast cancer with increasing alcohol intake. Pooled data from 118 individual studies indicates that light drinkers have a slightly increased (1.04-fold higher) risk of breast cancer, compared with nondrinkers. The risk increase is greater in moderate drinkers (1.23-fold higher) and heavy drinkers (1.6fold higher ${ }^{11,12}$ ).

Moderate to heavy alcohol consumption is associated with 1.2- to 1.5-fold increased risks of cancers of the colon and rectum

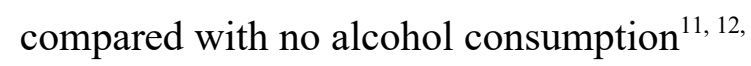
15. Alcohol consumption has also been associated with deceased risks of kidney cancers and non-Hodgkin lymphoma in multiple studies ${ }^{10}$.

\section{4-AMINOBIPHENYL}

Historically, occupational exposure to 4aminobiphenyl mainly occurred during its production and its use as a rubber antioxidant and dye intermediate. Occupational exposure can also occur when workers are exposed to products contaminated with 4-aminobiphenyl, or in 
the case of exposure to benzidine and benzidine-based dyes, from which 4aminobiphenyl can be metabolically released. The main sources of exposure to 4-aminobiphenyl for the general population are cigarette smoking and second-hand tobacco smoke, as 4aminobiphenyl is formed during tobacco combustion. Case reports and cohortsurveillance studies indicate a high occurrence of cancer of the urinary bladder in workers occupationally exposed to 4-aminobiphenyl, supported by evaluations of mortality in a chemical plant in the USA. Bladder cancer is strongly associated with occupational exposure to 4-aminobiphenyl ${ }^{16}$.

\section{ANALGESIC}

MIXTURES

\section{CONTAINING PHENACETIN}

There is sufficient evidence in experimental animals and humans for the carcinogenicity of analgesic mixtures containing phenacetin. These mixtures can cause cancer of the renal pelvis, and of the ureter ${ }^{17}$.

\section{ARISTOLOCHIC ACIDS (AAs)}

Aristolochic acids (abundant in the plants of genus Aristolochia and Asarum) are identified as a group of toxins that can cause end-stage renal failure associated with urothelial carcinoma. In 1992, a high prevalence of kidney disease accompanied by urothelial carcinoma in female patients ingesting slimming pills raised worldwide attention to the high nephrotoxic and carcinogenic potential of AAs. AA nephropathy is a kind of chronic tubulointerstitial renal disease accompanied by upper tract urothelial carcinoma in almost half of the cases. Balkan endemic nephropathy (rapidly progressive renal disease) has also been found to be associated with the exposure to Aas. Genomic heterogeneity analyses provide strong evidence that AAs potentially contribute to the development of liver cancer ${ }^{18}$.

\section{ARSENIC AND INORGANIC} ARSENIC COMPOUNDS

The International Agency for Research on Cancer (IARC), that is a part of the World Health Organization (WHO), classifies arsenic and inorganic arsenic compounds as carcinogenic to humans. This is based on sufficient evidence in humans that these compounds can cause lung, bladder and skin cancer. IARC also notes links in some studies to kidney, liver and prostate cancer. IARC classifies the organic arsenic compounds dimethylarsinic acid (also known as 
cacodylic acid) and monomethlyarsonic acid as possibly carcinogenic to humans ${ }^{19}$.

\section{ASBESTOS}

Asbestos is a unique mineral that can be pulled apart into flexible fibers. When a person inhales or swallows microscopic asbestos fibers, body cannot degrade or expel them. Over many years, the fibers cause inflammation and genetic changes that can lead to cancer. The most recent report from IARC confirms asbestos causes four types of cancer: mesothelioma, lung, laryngeal and ovarian cancers. The IARC also identified three types of cancer positively associated (some evidence of a link, but not strong enough data) with asbestos exposure: pharyngeal, stomach and colon cancer ${ }^{20}$.

\section{AZATHIOPRINE}

Pasternak and coworkers found in the study an approximately $40 \%$ increased rate of cancer associated with azathioprine use in patients with inflammatory bowel disease (IBD). This study confirmed a previously shown risk of lymphoma associated with azathioprine use in patients with IBD. They also found an almost 3fold significantly increased risk of urinary tract cancer among azathioprine users ${ }^{21}$.
Inman and coworkers found in the study strong case for an association between the drug azathioprine and the mutational signature found in cases of cutaneous squamous cell carcinoma ${ }^{22}$.

\section{BENZENE}

Benzene is a colorless or light-yellow liquid chemical at room temperature. It is used primarily as a solvent in the chemical and pharmaceutical industries, as a starting material and an intermediate in the synthesis of numerous chemicals, and in gasoline. Benzene is produced by both natural and man-made processes. It is a natural component of crude oil, which is the main source of benzene produced today. Other natural sources include gas emissions from volcanoes and forest fires. The exposure to benzene increases the risk of developing leukemia ${ }^{23}$.

Benzene causes acute myeloid leukemia and probably other hematological malignancies. Benzene also causes hematotoxicity even in workers exposed to levels below the US permissible occupational exposure limit of 1 part per million $^{24}$.

\section{BENZIDINE}

Benzidine is a manufactured chemical that does not occur in nature. In the past, large 
amounts of benzidine were used to produce dyes for cloth, paper, and leather. It was also used in clinical laboratories for detecting blood, as a rubber-compounding agent, and in the manufacture of plastic films. However, benzidine has not been sold in the United States since the mid1970s, and it is no longer used in medical laboratories or in the rubber and plastics industries ${ }^{25}$.

Benzidine (BZ) and beta-naphthylamine (BNA) have been classified as definite human carcinogens for bladder cancer by IARC. Tomioka and coworkers found in the study (systematic review and metaanalysis) that an occurrence of lung cancer following occupational BZ/BNA exposure should be considered to be a potential occupational disease ${ }^{26}$.

\section{BERYLLIUM AND BERYLLIUM COMPOUNDS}

Beryllium is a metal that is found in nature, especially in beryl and bertrandite rock. It is extremely lightweight and hard, is a good conductor of electricity and heat, and is non-magnetic. Because of these properties, beryllium is used in hightechnology consumer and commercial products, including aerospace components, transistors, nuclear reactors, and golf clubs. An increased risk of lung cancer has been observed in workers exposed to beryllium or beryllium compounds ${ }^{27}$.

\section{BIS(CHLOROMETHYL) ETHER AND TECHNICAL-GRADE \\ CHLOROMETHYL METHYL ETHER}

BCME and CMME are used primarily as chemical intermediates and alkylating agents. BCME is used as a laboratory reagent in the manufacture of plastics, ionexchange resins, and polymers. CMME is used as an alkylating agent and industrial solvent to manufacture dodecylbenzyl chloride, water repellants, ion-exchange resins, and polymers, and as a chloromethylating reagent. BCME is among the most potent animal and human carcinogens known. The fact that BCME and CMME are powerful alkylating agents provides moderate to strong evidence that they operate by a genotoxic mechanism of action. This mechanism is likely to be similar to that of other strong alkylating agents, involving modification of DNA and resultant mutations. Bis(chloromethyl)ether and chloromethyl methyl ether (technical grade) cause cancer of the lung ${ }^{28}$.

\section{1,3-BUTADIENE}

1,3-Butadiene is a colorless gas at room temperature with a gasoline-like odor. It is 
used to produce synthetic rubber products, such as tires, resins, and plastics, and other chemicals. Exposure to 1,3-butadiene mainly occurs among workers who breath contaminated air on the job. Other sources of exposure include automobile exhaust; tobacco smoke; and polluted air and water near chemical, plastic, or rubber facilities. Studies have consistently shown an association between occupational exposure to 1,3-butadiene and an increased incidence of leukemia ${ }^{29}$.

\section{1,4-BUTANEDIOL}

\section{DIMETHYLSULFONATE}

\section{(BUSULFAN)}

Busulfan is an antineoplastic agent with a cell-cycle nonspecific alkylating action that has a selective depressant action on the bone marrow. In small doses, it depresses granulocytopoiesis and to a lesser extent thrombocytopoiesis, but has little effect on lymphocytes. With larger doses, severe bone-marrow depression eventually ensues. Busulfan is indicated for the palliative treatment of chronic myelogenous leukemia. It provides symptomatic relief with a reduction in spleen size and a general feeling of wellbeing. The fall in leukocyte count is usually accompanied by a rise in the haemoglobin concentration. Permanent remission is not induced, and resistance to its beneficial effects gradually develops. Busulfan has been used in patients with polycythaemia vera, and in some patients with myelofibrosis and primary thrombocythaemia. It has also been used at high doses, orally, and more recently, intravenously, as part of a conditioning regimen to prepare patients for stem-cell transplantation. There is sufficient evidence in humans for the carcinogenicity of busulfan. It can cause acute myeloid leukemia ${ }^{30}$.

\section{CADMIUM AND CADMIUM COMPOUNDS}

Cadmium is a natural element found in tiny amounts in air, water, soil, and food. All soils and rocks, including coal and mineral fertilizers, contain some cadmium. Most cadmium used in the United States is extracted during the production of other metals such as zinc, lead, and copper. Cadmium does not corrode easily and has been used to manufacture batteries, pigments, metal coatings, and plastics. Exposure to cadmium occurs mostly in workplaces where cadmium products are made. The major routes of occupational exposure are inhalation of dust and fumes and incidental ingestion of dust from contaminated hands, cigarettes, or food. General population is exposed to cadmium 
by breathing tobacco smoke or eating cadmium-contaminated foods, which is the major source of cadmium exposure for nonsmokers. The expanding nickelcadmium ( $\mathrm{NiCd}$ ) battery recycling industry is also a potential source for exposure. Occupational exposure to various cadmium compounds is associated with an increased risk of lung cancer ${ }^{31}$.

Associations between cadmium exposure and tumors at other locations including kidney, breast, and prostate may be relevant as well ${ }^{32}$.

\section{CHLORAMBUCIL}

Chlorambucil is used primarily as an antineoplastic agent to treat cancer of the blood and lymphatic system, such as Hodgkin and non-Hodgkin lymphoma, chronic lymphocytic leukemia, and primary (Waldenström) macroglobulinemia. It is also used as a chemotherapeutic agent for Kaposi sarcoma and cancer of the breast, lung, cervix, ovary, and testis. Chlorambucil is an immunosuppressive agent that has been used to treat rheumatoid arthritis, systemic lupus erythematosus, acute and chronic glomerulonephritis, nephrotic syndrome, psoriasis, Wegener granulomatosis, chronic active hepatitis, and cold agglutinin disease (IARC 1981). Numerous case reports have linked treatment with chlorambucil, either alone or in combination with other therapies, with development of cancer, primarily acute non-lymphocytic leukemia, in patients who were treated for other types of cancer or other (nonmalignant) diseases ${ }^{33}$.

\section{SEMUSTINE}

Semustine or 1-(2-Chloroethyl)-3-(4methylcyclohexyl)-1-nitrosourea (MeCCNU) is an investigational drug used in chemotherapy to treat several types of cancers, including some brain cancers. It also has been used to treat cancers of the lung and digestive tract. The risk of developing leukemia or preleukemia following adjuvant treatment with methylCCNU during clinical trials was evaluated in 3,633 patients with gastrointestinal cancer. Fourteen cases of leukemic disorders were reported out of 2,067 patients given methyl-CCNU compared to only one case of acute non-lymphocytic leukemia out of 1,566 patients given other therapies (relative risk of over 12 fold). A strong dose-response relationship was shown in a later report; a relative risk of about 40 fold, adjusted for survival time, was found for patients treated with the highest dose of methyl-CCNU ${ }^{34}$. 


\section{CHROMIUM \\ HEXAVALENT COMPOUNDS}

Chromium is an odorless and tasteless metallic element that is found in the earth's crust. It is also found in air, water, soil, and food. Chromium hexavalent compounds have been used widely as corrosion inhibitors and in the manufacture of pigments, metal finishing and chrome plating, stainless steel production, leather tanning, and wood preservatives. They have also been used in textile-dyeing processes, printing inks, drilling muds, fireworks, water treatment, and chemical synthesis. Occupational exposure to hexavalent chromium can occur from inhalation of dusts, mists, or fumes containing hexavalent chromium, or from eye or skin contact. Industries with the largest number of workers exposed to high concentrations of airborne hexavalent chromium compounds include electroplating, welding, and chromate painting. Occupational exposure to these compounds is associated with increased risks of lung cancer, cancer of the paranasal sinuses and nasal cavity ${ }^{35}$.

\section{COAL TAR AND COAL-TAR PITCH}

Coal tar is derived from coal. It is a byproduct of the production of coke, a solid fuel that contains mostly carbon, and coal gas. Coal tar is used primarily for the production of refined chemicals and coaltar products, such as creosote and coal-tar pitch. Certain preparations of coal tar have long been used to treat various skin conditions, such as eczema, psoriasis, and dandruff. Coal-tar pitch is a thick black liquid that remains after the distillation of coal tar. It is used as a base for coatings and paint, in roofing and paving, and as a binder in asphalt products. Both coal tar and coal-tar pitch contain many chemical compounds, including carcinogens such as benzene. The primary routes of human exposure to coal tars and coal-tar products are inhalation, ingestion, and absorption through the skin. Exposure to coal tars and coal-tar pitches may occur at foundries and during coke production, coal gasification, and aluminum production. Other workers who may be exposed to coal-tar pitches include those who produce or use pavement tar, roofing tar, coal-tar paints, coal-tar enamels, other coal-tar coatings, or refractory bricks. General population may be exposed to coal tars in environmental contaminants and through the use of coal tar preparations to treat skin disorders such as eczema, psoriasis, and dandruff. Occupational exposure to coal tar or coaltar pitch increases the risk of skin cancer. 
Other types of cancer, including lung, bladder, kidney, and digestive tract cancer, have also been linked to occupational exposure to coal tar and coal$\operatorname{tar}$ pitch $^{36}$.

\section{COKE OVEN EMISSIONS}

Coke oven emissions come from large ovens that are used to heat coal to produce coke, which is used to manufacture iron and steel. The emissions are complex mixtures of dust, vapors, and gases that typically include carcinogens such as cadmium and arsenic. Chemicals recovered from coke oven emissions are used as raw materials for producing items such as plastics, solvents, dyes, paints, and insulation. Workers at coking plants and coal-tar production plants may be exposed to coke oven emissions. Occupational exposures can also occur among workers in the aluminum, steel, graphite, electrical, and construction industries. The primary routes of potential human exposure to coke oven emissions are inhalation and absorption through the skin. Exposure to coke oven emissions increases the risk of lung cancer and, possibly, kidney cancer $^{37}$.

\section{CYCLOPHOSPHAMIDE}

Cyclophosphamide is an antineoplastic agent metabolized to active alkylating metabolites with properties similar to those of chlormethine. Cyclophosphamide is used in the treatment of Hodgkin lymphoma, non-Hodgkin lymphoma (including Butkitt and lymphoblastic lymphoma), multiple myeloma, chronic lymphocytic leukemia, acute lymphoblastic and myeloid leukemia, advanced mycosis fungoides, disseminated neuroblastoma, ovarian germ-cell tumors, advanced epithelial ovarian cancer, retinoblastoma, breast cancer, small cell lung cancer and sarcoma. Cyclophosphamide, after its bioactivation to alkylating metabolites, is carcinogenic via a genotoxic mechanism. There is sufficient evidence in humans for the carcinogenicity of cyclophosphamide. It can cause cancer of the bladder, and acute myeloid leukaemia ${ }^{38}$.

\section{CYCLOSPORIN A}

Cyclosporin $\mathrm{A}$ is used extensively in the prevention and treatment of graft-versushost reactions in bone-marrow transplantation and to prevent rejection of kidney, heart, and liver transplants. It is also used as an ophthalmic emulsion for 
the topical treatment of dry eye syndrome. Numerous case reports describe cancer, mainly lymphoma, Kaposi sarcoma, or skin cancer, developing in organtransplant recipients, psoriasis patients, and rheumatoid arthritis patients treated with cyclosporin $\mathrm{A}$ as an immunosuppressive agent. Some of these patients were treated with cyclosporine alone, whereas others were treated with other immunosuppressive agents in combination with cyclosporin. The time between the start of treatment and development of tumors ranged from 1 month to 10 years. In some cases, tumors regressed after treatment with cyclosporin A was discontinued. Several epidemiological studies (cohort studies) also indicate that cyclosporin A is carcinogenic in humans, causing tumors at an incidence of less than $5 \%$ in the patient population ${ }^{39}$.

\section{DIETHYLSTILBESTROL}

Diethylstilbestrol (DES) was the first synthetic estrogen used to prevent miscarriages. Women who took DES have been found to have a moderately increased risk of developing breast cancer. Daughters of the women who took DES are at risk for developing a rare form of vaginal or cervical cancer called clear cell adenocarcinoma. Though the risk is
40 times that of someone not exposed, this translates to 1 in every 1000 women exposed $^{40}$.

\section{EPSTEIN-BARR VIRUS (EBV)}

Epstein-Barr virus contributes to about $1.5 \%$ of all cases of human cancer worldwide, and viral genes are expressed in the malignant cells. EBV also very efficiently causes the proliferation of infected human B lymphocytes ${ }^{41}$.

EBV can be linked to Hodgkin lymphoma, Burkitt lymphoma and nasopharyngeal cancer ${ }^{42}$.

\section{ERIONITE}

Erionite is a naturally occurring fibrous mineral that belongs to a group of minerals called zeolites. It forms fibrous masses in the hollows of rock formations. Some of the mineral's properties are similar to those of asbestos; for example, the fibers pose a hazard only if they are disturbed and become airborne. In the past, occupational exposure occurred during erionite mining and production operations, but erionite is no longer mined or marketed for commercial purposes. Erionite-related disease has been reported most often among road construction and maintenance workers who may have been exposed to erionite-containing gravel used in road 
surfacing. The commercial uses of other natural zeolites include pet litter, soil conditioners, animal feed, wastewater treatment, and gas absorbents. Exposure to erionite is associated with an increased risks of lung cancer and mesothelioma ${ }^{43}$.

\section{STEROIDAL ESTROGENS}

Hormone therapy (that contains estrogens) is widely used by millions of women to relieve symptoms of menopause, but it has been associated with several side effects such as coronary heart disease, stroke and increased invasive breast cancer risk ${ }^{44}$.

\section{ETHYLENE OXIDE}

At room temperature, ethylene oxide is a flammable colorless gas with a sweet odor. It is used primarily to produce other chemicals, including antifreeze. In smaller amounts, ethylene oxide is used as a pesticide and a sterilizing agent. The ability of ethylene oxide to damage DNA makes it an effective sterilizing agent but also accounts for its cancer-causing activity. The primary routes of human exposure to ethylene oxide are inhalation and ingestion, which may occur through occupational, consumer, or environmental exposure. Because ethylene oxide is highly explosive and reactive, the equipment used for its processing generally consists of tightly closed and highly automated systems, which decreases the risk of occupational exposure. Lymphoma and leukemia are the cancers most frequently reported to be associated with occupational exposure to ethylene oxide. Stomach and breast cancers may also be associated with ethylene oxide exposure ${ }^{45}$.

\section{FORMALDEHYDE}

Formaldehyde is a colorless, strongsmelling, flammable chemical that is produced industrially and used in building materials such as particleboard, plywood, and other pressed-wood products. In addition, it is commonly used as a fungicide, germicide, and disinfectant, and as a preservative in mortuaries and medical laboratories. Formaldehyde also occurs naturally in the environment. It is produced during the decay of plant material in the soil and during normal chemical processes in most living organisms. It is also a combustion product found in tobacco smoke. People are exposed primarily by inhaling formaldehyde gas or vapor from the air or by absorbing liquids containing formaldehyde through the skin. Workers who produce formaldehyde or products that contain formaldehyde - as well as laboratory technicians, certain health care 
professionals, and mortuary employeesmay be exposed to higher levels of formaldehyde than people in the general population. The general public may be exposed to formaldehyde by breathing contaminated air from sources such as pressed-wood products, tobacco smoke, and automobile tailpipe emissions. Another potential source of exposure to formaldehyde is the use of unvented fuelburning appliances, such as gas stoves, wood-burning stoves, and kerosene heaters. Studies of workers exposed to high levels of formaldehyde, such as industrial workers and embalmers, have found that formaldehyde causes myeloid leukemia and rare cancers, including cancers of the paranasal sinuses, nasal cavity, and nasopharyn $x^{46}$.

\section{HELICOBACTER PYLORI}

H. pylori is a bacteria that infects the lining of the stomach. It is spread through contaminated food and water and normally infects people during childhood. H. pylori can cause long-lasting inflammation in the stomach (severe chronic atrophic gastritis) and stomach ulcers. This can lead to development of cancer. H. pylori infection is linked to several cancers: stomach cancer (especially a type called non-cardia gastric cancer), non-Hodgkin lymphoma, bowel cancer and esophageal cancer ${ }^{47}$.

\section{HEPATITIS B VIRUS}

In contrast to a majority of cancer types, the initiation of hepatocellular carcinoma (HCC) is intimately associated with a chronically diseased liver tissue, with one of the most prevalent etiological factors being hepatitis $\mathrm{B}$ virus (HBV). Transformation of the liver in HBVassociated HCC often follows from or accompanies long-term symptoms of chronic hepatitis, inflammation and cirrhosis, and viral load is a strong predictor for both incidence and progression of HCC. Besides aiding in transformation, HBV plays a crucial role in modulating the accumulation and activation of both cellular components of the microenvironment, such as immune cells and fibroblasts, and non-cellular components of the microenvironment, such as cytokines and growth factors, markedly influencing disease progression and prognosis ${ }^{48}$.

\section{HEPATITIS C VIRUS}

Most hepatitis C virus (HCV) infection results in persistent infection. Significant portion of chronic $\mathrm{HCV}$-infected patients develop hepatocellular carcinoma. 
Chronic hepatitis $\mathrm{C}$ is also associated with extrahepatic manifestations, including cryoglobulinemia, lymphoma, insulin resistance, type 2 diabetes, and neurological disorders. The molecular mechanisms of how HCV infection causes liver cancer are largely unknown. HCV replication or viral proteins may perturb cellular hemostasis and induce the generation of reactive oxygen species; viral components or viral replication products act as agonist to trigger innate immune response and cause chronic inflammation. Within the liver, non-hepatocytes such as hepatic stellate cell are activated upon $\mathrm{HCV}$ infection to provide the major source of extracellular proteins and play important roles in fibrogenesis. With the great achievements of HCV treatment, especially the direct-acting antivirals against $\mathrm{HCV}$, $\mathrm{HCV}$ eradication is possible ${ }^{49}$.

\section{HUMAN IMMUNODEFICIENCY VIRUS TYPE 1}

The human immunodeficiency virus causes acquired immune deficiency syndrome (AIDS). The virus can be spread through blood-to-blood contact (sharing needles, razors, toothbrushes, unprotected sex, mother-to-child transmission). HIV infection is associated with the development of Kaposi sarcoma, lymphomas, eye cancer, cervical and anal cancers ${ }^{50}$.

\section{HUMAN PAPILLOMA VIRUSES}

Human papilloma viruses (HPV) is a group of more than 200 related viruses, some of which are spread through vaginal, anal, or oral sex. Sexually transmitted HPV types fall into two groups, low risk and high risk. Low-risk HPVs mostly cause no disease. However, a few low-risk HPV types can cause warts on or around the genitals, anus, mouth, or throat. High-risk HPVs can cause several types of cancer. There are about 14 high-risk HPV types. Two of these, HPV16 and HPV18, are responsible for most HPV-related cancers.

HPV-related cancers include:

1) Cervical cancer: virtually all cervical cancers are caused by high-risk HPVs.

2) Oropharyngeal cancers: approximately $70 \%$ of all oropharyngeal cancers in the United States are caused by HPVs.

3) Anal cancer: over $90 \%$ of anal cancers are caused by HPVs.

4) Penile cancer: over $60 \%$ of penile cancers are caused by HPVs. 
5) Vaginal cancer: approximately $75 \%$ of all vaginal cancers are caused by HPVs.

6) Vulvar cancer: approximately $70 \%$ of all vulvar cancers are caused by HPVs ${ }^{51}$.

\section{HUMAN T-CELL LYMPHOTROPIC VIRUS TYPE 1}

Human T-cell leukemia virus-1 (HTLV-1) is the first pathogenic human retrovirus identified in 1979 by the Gallo group. HTLV-1 causes fatal T-cell leukemia (adult $\mathbf{T}$ cell leukemia) and a progressive myelopahy (HTLV-1-associated myelopathy/tropical spastic paraparesis) and other disorders. HTLV-1 is one of the most and may be the most carcinogenic among carcinogenic microorganisms and arguably one of the most potent of the known human carcinogens ${ }^{52}$.

\section{KAPOSI SARCOMA-ASSOCIATED HERPES VIRUS}

The human herpesvirus $8(\mathrm{HHV}-8)$ is the oncogenic virus associated with Kaposi sarcoma (KS) and lymphoproliferative disorders, namely, primary effusion lymphoma and multicentric Castleman disease. $\mathrm{KS}$ is among the most common malignancies seen in HIV-infected patients despite the decreased incidence of $\mathrm{KS}$ in the era of highly active antiretroviral therapy. Advances in molecular pathology reveal HHV-8 tumorigenesis is mediated through molecular mimicry wherein viralencoded proteins can activate several cellular signaling cascades while evading immune surveillance ${ }^{53}$.

\section{MELPHALAN}

Melphalan is an antineoplastic agent that acts as a bifunctional alkylating agent. It is used in the treatment of multiple myeloma, advanced ovarian adenocarcinoma, early and advanced breast cancer, childhood neuroblastoma, and polycythaemia vera. Melphalan is also used for regional arterial perfusion in localized malignant melanoma, and localized soft-tissue sarcoma of the extremities. Melphalan is a direct-acting alkylating agent that is carcinogenic via a genotoxic mechanism. There is sufficient evidence in humans for the carcinogenicity of melphalan. It can cause acute myeloid leukaemia ${ }^{54}$.

\section{MERKEL CELL POLYOMAVIRUS}

Merkel cell polyomavirus (MCPyV) causes the highly aggressive and relatively rare skin cancer known as Merkel cell carcinoma. MCPyV also causes a lifelong 
yet relatively innocuous infection and is one of 14 distinct human polyomaviruses species. Although polyomaviruses typically do not cause illness in healthy individuals, several can cause catastrophic diseases in immunocompromised hosts. $\mathrm{MCPyV}$ is the only polyomavirus clearly associated with human cancer ${ }^{55}$.

\section{METHOXSALEN \\ WITH \\ ULTRAVIOLET A THERAPY (PUVA)}

PUVA is used in the treatment of psoriasis, cutaneous T-cell lymphoma, idiopatic vitiligo and chronic graft-versus-host disease. Methoxsalen in combination with UVA is carcinogenic via a genotoxic mechanism that involves photo-activation. There is sufficient evidence in humans for the carcinogenicity of PUVA. It can cause squamous cell carcinoma of the skin $^{56}$.

\section{MINERAL OILS}

The name mineral oil has been used to describe many colorless, odorless liquids. Most often, the term refers to a liquid byproduct of the distillation of petroleum to produce gasoline and other petroleumbased products from crude oil. These oils, including lubricant base oils and products derived from them, are used in manufacturing, mining, construction, and other industries. Oils used in cosmetic products are typically highly refined, whereas those used in automotive oils and fluids tend to be unrefined or only mildly treated. Occupational exposure to mineral oils may occur among workers in various industries, including the manufacture of automobiles, airplanes, steel products, screws, pipes, and transformers. Workers in brass and aluminum production, engine repair, copper mining, and newspaper and commercial printing may also be exposed to mineral oils. General population may be exposed to mineral oils that occur naturally or are present as environmental contaminants. Exposure to untreated or mildly treated mineral oils is strongly associated with an increased risk of nonmelanoma skin cancer, particularly of the scrotum ${ }^{57}$.

\section{MUSTARD GAS}

Sulfur mustard (SM), also known as mustard gas, is an alkylating compound used as a chemical weapon in World War I and by Iraqi forces against Iranians and indigenous Iraqi Kurds during the Iran-Iraq War of the 1980s. SM is a proven carcinogen. Even a single exposure can increase the risk of lung cancer development in some individuals ${ }^{58}$. 


\section{2-NAPHTHYLAMINE}

2-Naphthylamine formerly was used commercially as intermediate in the manufacture of dyes, as an antioxidant in the rubber industry, and to produce 2chloronaphthalene (IARC, 2010). Because of its carcinogenicity, the manufacture and use of 2-naphthylamine have been prohibited in the European Union (EU) since 1998, in Italy since 1960, in the United Kingdom since 1952, and in Switzerland since 1938. Production and use of dyestuffs containing 2naphthylamine have been banned in Japan since 1972. In the United States of America, 2-naphthylamine is a carcinogen regulated by the Occupational Safety and Health Administration. As such, exposure must be strictly controlled through mandatory use of engineering controls, safe work practices, and personal protective equipment. There is sufficient evidence in humans for the carcinogenicity of 2-naphthylamine. It can cause cancer of the urinary bladder. There is strong mechanistic evidence indicating that the carcinogenicity of 2-naphthylamine operates by a genotoxic mechanism of action that involves metabolic activation, formation of DNA adducts, and induction of mutagenic and clastogenic effects. Metabolic activation to DNA-reactive intermediates occurs by multiple pathways including $\mathrm{N}$-oxidation in the liver, $\mathrm{O}$ acetylation in the bladder, and peroxidative activation in the mammary gland and other organs ${ }^{59}$.

\section{NEUTRONS}

Neutron therapy is a highly effective form of radiation therapy used in the cancer treatment. Different types of ionizing radiation produce different dependences of cancer risk on radiation dose/dose rate. Densely ionizing radiation (neutrons) often produces downwardly curving dose responses, where the risk initially grows with dose, but eventually stabilizes or decreases. When the dose rate is reduced, the risk increases (inverse dose rate effect). For densely ionizing radiation the dominant mechanism of carcinogenesis is radiation-bystander-effect mediated promotion of already pre-malignant cell clone growth ${ }^{60}$.

\section{NICKEL COMPOUNDS}

Nickel is a silvery-white metallic element found in the earth's crust. It can be combined with other elements to form nickel compounds. Because of its unique properties, nickel has many industrial uses. Most nickel is used in metal alloys because it imparts useful properties, such as 
corrosion resistance, heat resistance, hardness, and strength. Occupational exposure is common in workplaces where nickel and nickel compounds are produced or used, including mining, smelting, welding, casting, and grinding. Occupational exposure to nickel occurs mainly through inhalation of dust particles and fumes or through skin contact. General population is exposed to low levels of nickel in air, water, food, and tobacco smoke. Nickel and its compounds get into the atmosphere through natural processes, such as the spread of dust and volcanic eruptions by the wind, as well as through industrial activities. The general public may also be exposed through nickel-plated materials, such as coins, jewelry, and stainless steel cooking and eating utensils. Exposure to various nickel compounds increases the risk of lung cancer and nasal cancer ${ }^{61}$.

\section{RADON}

Radon is a radioactive gas that is released from the normal decay of the elements uranium, thorium, and radium in rocks and soil. The invisible, odorless gas seeps up through the ground and diffuses into the air. In a few areas, depending on local geology, radon dissolves into ground water and can be released into the air when the water is used. Radon gas usually exists at very low levels outdoors, but the gas can accumulate in areas without adequate ventilation, such as underground mines. Radon is present in nearly all air, so everyone breathes in radon every day, usually at very low levels. Radon can enter homes through cracks in floors, walls, or foundations, and collect indoors. It can also be released from building materials or from water obtained from wells that contain radon. Radon levels may be higher in homes that are well insulated, tightly sealed, and/or built on soil rich in the elements uranium, thorium, and radium. Basements and first floors typically have the highest radon levels because of their closeness to the ground. Workers employed in uranium, hard rock, and phosphate mining, are potentially exposed to radon at high concentrations. Uranium miners generally are believed to have the highest exposures. Radon was identified as a health problem when scientists noted that underground uranium miners who were exposed to it died of lung cancer at high rates. Experimental studies in animals confirmed the results of the miner studies by showing higher rates of lung tumors among rodents exposed to high levels of radon. There has been a suggestion of an increased risk of leukemia associated with 
radon exposure in adults and children, but the evidence is not conclusive ${ }^{62}$.

\section{SILICA DUST}

An abundant natural material, crystalline silica is found in stone, soil, and sand. It is also found in concrete, brick, mortar, and other construction materials. Crystalline silica comes in several forms, with quartz being the most common. Quartz dust is respirable crystalline silica. Exposure to tiny particles of airborne silica, primarily quartz dust, occurs mainly in industrial and occupational settings. When inhaled, these particles can penetrate deep into the lungs. The primary route of exposure for the general population is inhaling airborne silica while using commercial products containing quartz. These products include cleansers, cosmetics, art clays and glazes, pet litter, talcum powder, caulk, and paint. Exposure of workers to respirable crystalline silica is associated with elevated rates of lung cancer ${ }^{63}$.

\section{SOLAR RADIATION}

Solar radiation is of fundamental importance for human development and health. On the one hand, too much of it can lead to skin ageing and skin cancer, whilst on the other hand, too little of it can result in vitamin D deficiency, and, thereby lead to high incidence and poor prognosis of internal cancer as well as a number of other diseases. Moan and coworkers conducted a study in Norway and concluded that:

1) Vitamin D level varies with season, but probably not with latitude in Norway, because of an increased intake of vitamin $\mathrm{D}$ in the north.

2) Skin cancer incidence rates increase from north to south, as do annual influence rates of UV radiation, while there seems to be a slight improvement in prognosis from north to south.

3) Prognosis of internal cancer is best for cases diagnosed in the seasons with the best vitamin $\mathrm{D}$ status (summer and autumn).

4) Incidence rates of cutaneous melanomas have increased from 1960 to 1990 , but have decreased slightly thereafter for young people.

5) Changes in sun exposure habits have taken place.

6) An increase in body mass index (BMI) of the population has occurred, which may have led to a worsening of the vitamin D status $^{64}$. 
When it comes to exposure to solar radiation, the dose of radiation is very important, because both too high exposure (increased risk for skin cancers, especially melanoma) and too low exposure (low vitamin D status, increased risk for autoimmune diseases, higher mortality rates for cancer patients) are potentially dangerous.

\section{SOOTS}

Soot is a byproduct of the incomplete burning of organic (carbon-containing) materials, such as wood, fuel oil, plastics, and household refuse. The fine black or brown powder that makes up soot may contain a number of carcinogens, including arsenic, cadmium and chromium. People may be exposed to soot by inhalation, ingestion, or absorption through the skin. Chimney sweeps likely have the highest occupational exposure to soot. Heatingunit service personnel, brick masons, building demolition personnel, horticulturists, and anyone who works where organic materials are burned may also be exposed through their work. The general public may be exposed through fireplaces, furnaces, engine exhaust, and particulate emissions from any combustion source. Exposure to soot was first associated with skin cancer of the scrotum among British chimney sweeps in 1775. Since then, many studies have found that chimney sweeps have an increased risk of scrotal and other skin cancers. Studies of chimney sweeps in several European countries have also found associations with other cancers, including lung, esophageal, and bladder cancers ${ }^{65}$.

\section{STRONG INORGANIC ACID MISTS CONTAINING SULFURIC ACID}

At room temperature, sulfuric acid is a clear, colorless, oily, corrosive liquid. Strong inorganic acid mists containing sulfuric acid may be generated during various manufacturing processes. The major routes of occupational exposure are inhalation, ingestion, or absorption through the skin. Workers with potential exposure include those involved in manufacturing phosphate fertilizer, isopropanol, sulfuric acid, nitric acid, and lead batteries. Exposure may also occur during copper smelting, pickling (removing scale and oxides from metal surfaces), and other acid treatment of metals. Occupational exposure to strong inorganic acid mists containing sulfuric acid is associated with an increased risks of laryngeal and lung cancers $^{66}$. 


\section{SUNLAMPS AND SUNBEDS}

Sunbed/sunlamp use is classified as carcinogenic. The report from 2011 (Fears and coworkers) considers characteristics of those who use sunbeds/sunlamps and the effect of sunbed/sunlamp use on their risk for melanoma within a large case-control study carried out in 1991-2. Females were more likely than males to have used sunbeds/sunlamps. Use by females increased strongly and significantly with younger ages and with the perceived ability to tan. For females the individual risk for melanoma increased with typical session time and frequency of sessions. Use before age 20, current use and years of use were not significant. The use patterns of occasional and frequent users were very different. Authors estimated that typical 5 minute sessions would increase the risk for melanoma by $19 \%$ for frequent users $(10+$ sessions) and by 3\% for occasional users (1-9 sessions). Body sites that are not generally exposed to sunlight were more common sites of primary melanomas for frequent sunbed/sunlamp users. For males, measures of sunbed/sunlamp use were not significantly associated with melanoma risk $^{67}$.

\section{TAMOXIFEN}

Tamoxifen is an anti-estrogenic drug widely used for adjuvant therapy of breast cancer. Its use has caused an increased incidence of endometrial cancer and it is also a potent carcinogen in rat liver ${ }^{68}$.

\section{DIOXIN (TCDD)}

Dioxin (2,3,7,8-tetrachlorodibenzo-pdioxin) is highly toxic environmental persistent organic pollutant. It is byproduct of various industrial processes. $\mathrm{Xu}$ and coworkers' findings suggest that external exposure and blood level of TCDD were both significantly associated with all cancer mortality. Higher external exposure of TCDD may significantly increase the mortality rate of esophagus cancer, larynx cancer, kidney cancer, non-Hodgkin lymphoma, myeloma, and soft-tissue sarcoma ${ }^{69}$.

\section{THIOTEPA}

Thiotepa suppresses cell growth and division and was introduced in 1953 for use in cancer chemotherapy to treat lymphoma and a variety of solid and softtissue tumors. Exposure to thiotepa is specifically associated with leukemia in humans. Adamson and Seiber (1981) summarized nine case reports from 1970 to 1978 of secondary development of non- 
lymphocytic leukemia in patients with primary cancer at other sites who had received only thiotepa as a therapeutic agent. Additional evidence was provided by a case-control study which found that patients treated with thiotepa were significantly more likely to develop secondary leukemia than those undergoing surgery alone (IARC 1990) $)^{70}$.

\section{THORIUM DIOXIDE}

Thorium is a naturally occurring radioactive metal found in soil, rock, and water. It is formed by the radioactive decay of uranium. Minerals such as monazite, thorite, and thorianite are rich in thorium and may be mined for the metal. Thorium has coloring properties that have made it useful in ceramic glazes. Thorium also has been widely used in lantern mantles for the brightness it imparts (though alternatives are replacing it), and in welding rods, which burn better with small amounts of added thorium. Until the 1950s, thorium dioxide was used as a contrast agent (called Thorotrast) in medical radiology. The primary ways people are exposed to thorium are inhalation, intravenous injection, ingestion, and absorption through the skin. More than 2.5 million people worldwide were exposed to thorium in Thorotrast between 1930 and 1950.
Once injected, Thorotrast remains in the body, resulting in lifelong exposure to thorium. Although thorium is widespread in the environment, most people are not exposed to dangerous levels of the metal. However, people who live near thoriummining areas or facilities that manufacture products with thorium may have increased exposure, especially if their water comes from a private well. Studies of patients who received intravascular injections of Thorotrast found an increased risk of liver tumors among these individuals. There is research evidence that inhaling thorium dust increases the risk of lung and pancreatic cancer. Individuals exposed to thorium also have an increased risk of bone cancer because thorium may be stored in bone $\mathrm{e}^{71}$.

\section{TOBACCO}

Tobacco use is a leading cause of cancer and of death from cancer. People who use tobacco products or who are regularly around environmental tobacco smoke (also called secondhand smoke) have an increased risk of cancer because tobacco products and secondhand smoke have many chemicals that damage DNA. Tobacco use causes many types of cancer, including cancer of the lung, larynx, mouth, esophagus, throat, bladder, 
kidney, liver, stomach, pancreas, colon and rectum, and cervix, as well as acute myeloid leukemia. People who use smokeless tobacco (snuff or chewing tobacco) have increased risks of cancers of the mouth, esophagus, and pancreas ${ }^{72}$.

\section{$o$-TOLUIDINE}

ortho-Toluidine (o-Toluidine) is an aromatic amine used primarily in the manufacture of dyestuffs, and in the production of synthetic rubber, chemicals and pesticides, and as a curing agent for epoxy resin systems. $o$-Toluidine was classified by IARC as carcinogenic to humans (Group 1). The study from 2014 (Carreón and coworkers) showed a nearthreefold excess of bladder cancer among workers considered exposed to $o$-toluidine, aniline and nitrobenzene in a chemical manufacturing plant, when compared with the New York State population. They observed a fourfold increase in bladder cancer among workers probably exposed (low and regularly), and an almost fourfold increase among those definitely exposed $\left(\right.$ moderate/high $\left.{ }^{73}\right)$.

\section{TRICHLOROETHYLENE}

Trichloroethylene (TCE) is a volatile, colorless liquid organic chemical. TCE does not occur naturally and is created by chemical synthesis. It is used primarily to make refrigerants and other hydrofluorocarbons and as a degreasing solvent for metal equipment. TCE is also used in some household products, such as cleaning wipes, aerosol cleaning products, tool cleaners, paint removers, spray adhesives, and carpet cleaners and spot removers. Commercial dry cleaners also use trichloroethylene as a spot remover. TCE may be found in the air, water, and soil at places where it is produced or used. It breaks down slowly and remains in the environment for a long time. It readily passes through soil and can accumulate in groundwater. People in the general population can be exposed to TCE by inhaling it in indoor and outdoor air, drinking contaminated water, or eating foods that have been washed or processed with contaminated water. People who work with TCE may inhale the chemical from the air and absorb it through the skin. Historically, TCE was used as a surgical anesthetic and inhaled analgesic. The Food and Drug Administration banned such use in the United States in 1977. Prolonged or repeated exposure of TCE causes kidney cancer. Some evidence suggests that it may be associated with an increased risks of non-Hodgkin lymphoma and, possibly, liver cancer $^{74}$. 


\section{VINYL CHLORIDE}

Vinyl chloride is a colorless gas that burns easily. It does not occur naturally and must be produced industrially for its commercial uses. Vinyl chloride is used primarily to make polyvinyl chloride (PVC) that is used to make a variety of plastic products, including pipes, wire and cable coatings, and packaging materials. Vinyl chloride is also produced as a combustion product in tobacco smoke. Workers at facilities where vinyl chloride is produced or used may be exposed primarily through inhalation. The general population may be exposed by inhaling contaminated air or tobacco smoke. In the environment, the highest levels of vinyl chloride are found in air around factories that produce vinyl products. If a water supply is contaminated, vinyl chloride can enter household air when the water is used for showering, cooking, or laundry. Vinyl chloride exposure is associated with an increased risk of hepatic angiosarcoma, as well as brain and lung cancers, lymphoma and leukemia ${ }^{75}$.

\section{WOOD DUST}

Wood dust is created when machines or tools are used to cut or shape wood. High amounts of wood dust are produced in sawmills, and in the furniture-making, cabinet-making, and carpentry industries. Individuals who use machinery or tools to cut or shape wood are exposed to wood dust. When the dust is inhaled, it is deposited in the nose, throat, and other airways. Occupations with high exposure to wood dust include sander operators in the transportation equipment industry, press operators in the wood products industry, lathe operators in the furniture industry, and sander operators in the wood cabinet industry. Strong and consistent associations with cancers of the paranasal sinuses and nasal cavity have been observed both in studies of people whose occupations were associated with wood-dust exposure and in studies that directly estimated wood-dust exposure ${ }^{76}$.

\section{X-RADIATION AND GAMMA RADIATION}

$\mathrm{X}$-rays and gamma rays are known human carcinogens. Studies have found an increased risk of the following cancers (from higher to lower risk):

1) Most types of leukemia (although not chronic lymphocytic leukemia)

2) Multiple myeloma

3) Thyroid cancer 
4) Bladder cancer

5) Breast cancer

6) Lung cancer

7) Ovarian cancer

8) Colon cancer (but not rectal cancer)

9) Esophageal cancer

10) Stomach cancer

11) Liver cancer

12) Lymphoma

13) Skin cancer (besides melanoma) ${ }^{77}$

\section{DISCUSSION}

\section{The Knudson hypothesis (two-hit} hypothesis) explains that most tumor suppressor genes require both alleles to be inactivated, either through mutations or through epigenetic silencing, to cause a phenotypic change ${ }^{78}$.

Human carcinogens (toxins) can cause both a first hit (mutation) and a second hit (epigenetic silencing in the case of tumor suppressor genes, or enhancement in the case of tumor oncogenes), and therefore, play a very important role in cancer pathogenesis.
Toxins can be found everywhere, in the environment, in household products, in food, in cosmetics...Even drugs can be toxins (as showed here in this review) and act as potential or known human carcinogens. Therefore, toxicology is very important part of multidisciplinary approach to cancer research and it is also very important for clinical practice, because every drug can be a potential toxin, depending on the dose and duration of its use.

The role of toxicology is to investigate all potential health hazards related to toxins, and to improve the industry and everyday life in a way that lowers the risk of occupational and non-occupational exposure to toxins. The lower is the exposure of the population to human carcinogens, the lower should be the risk of the cancer development. Therefore, raising awareness of the importance of toxins and their role as human carcinogens is important factor for the improvement of human health.

It is also very important to continue the investigation on possible human carcinogens in order to determine the clinical relevance of every possible human carcinogen and its association with health hazards. It is also important to determine 
the toxic dose for every molecule, to which humans are exposed to, including the cumulative toxicity, what is especially important for molecules or physical powers, such as solar irradiation, that can be both very useful (for example, vitamin D synthesis), and very dangerous (increased risk for the development of melanoma) depending on the dose and duration of exposure.

\section{REFERENCES}

1. Stone TW, Darlington LG. Microbial carcinogenic toxins and dietary anti-cancer protectants. Cell Mol Life Sci. 2017;74(14):26272643.

2. Known and Probable Human Carcinogens. August 14, 2019. Retrieved from https://www.cancer.org/cancer/cancercauses/general-info/known-and-probable-humancarcinogens.html (cited on October 17, 2021)

3. Marchese S, Polo A, Ariano A, et al. Aflatoxin B1 and M1: Biological Properties and Their Involvement in Cancer Development. Toxins (Basel). 2018;10(6):214.

4. Nugraha A, Khotimah K, Rietjens IMCM. Risk assessment of aflatoxin B1 exposure from maize and peanut consumption in Indonesia using the margin of exposure and liver cancer risk estimation approaches. Food Chem Toxicol. 2018;113:134144.

5. Hayes RB, van Nieuwenhuize JP, Raatgever JW, ten Kate FJ. Aflatoxin exposures in the industrial setting: an epidemiological study of mortality. Food Chem Toxicol. 1984;22(1):39-43.

6. Harrison JC, Carvajal M, Garner RC. Does aflatoxin exposure in the United Kingdom constitute a cancer risk? Environ Health Perspect. 1993;99:99-105.

7. Koshiol J, Gao YT, Dean M, et al. Association of Aflatoxin and Gallbladder Cancer. Gastroenterology. 2017;153(2):488-494.e1.

8. Ghasemi-Kebria F, Joshaghani H, Taheri NS, et al. Aflatoxin contamination of wheat flour and the risk of esophageal cancer in a high risk area in Iran. Cancer Epidemiol. 2013;37(3):290-3.

9. Eom SY, Yim DH, Zhang Y, et al. Dietary aflatoxin B1 intake, genetic polymorphisms of CYP1A2, CYP2E1, EPHX1, GSTM1, and GSTT1, and gastric cancer risk in Korean. Cancer Causes Control. 2013; 24(11):1963-72.

10. Alcohol and Cancer Risk. National Cancer Institute. September 13, 2018. Retrieved from https://www.cancer.gov/about-cancer/causesprevention/risk/alcohol/alcohol-fact-sheet (cited on October 17, 2021)

11. Bagnardi V, Rota M, Botteri E, et al. Alcohol consumption and site-specific cancer risk: a comprehensive dose-response meta-analysis. $\mathrm{Br} J$ Cancer. 2015;112(3):580-593.

12. LoConte NK, Brewster AM, Kaur JS, et al. Alcohol and cancer: A statement of the American Society of Clinical Oncology. $J$ Clin Oncol. 2018;36(1):83-93.

13. Grewal P, Viswanathen VA. Liver cancer and alcohol. Clin Liver Dis. 2012;16(4):839-850.

14. Petrick JL, Campbell PT, Koshiol J, et al. Tobacco, alcohol use and risk of hepatocellular carcinoma and intrahepatic cholangiocarcinoma: 
The Liver Cancer Pooling Project. Br J Cancer. 2018;118(7):1005-1012.

15. Fedirko V, Tramacere I, Bagnardi V, et al. Alcohol drinking and colorectal cancer risk: an overall and dose-response meta-analysis of published studies. Ann Oncol. 2011;22(9):19581972.

16. IARC Working Group on the Evaluation of Carcinogenic Risk to Humans. Chemical Agents and Related Occupations. Lyon (FR): International Agency for Research on Cancer; 2012. (IARC Monographs on the Evaluation of Carcinogenic Risks to Humans, No. 100F.) 4AMINOBIPHENYL. Available at https://www.ncbi.nlm.nih.gov/books/NBK304408/

17. IARC Working Group on the Evaluation of Carcinogenic Risk to Humans. Pharmaceuticals. Lyon (FR): International Agency for Research on Cancer; 2012. (IARC Monographs on the Evaluation of Carcinogenic Risks to Humans, No. 100A.) PHENACETIN. Available at https://www.ncbi.nlm.nih.gov/books/NBK304337/

18. Han J, Xian Z, Zhang Y, et al. Systematic Overview of Aristolochic Acids: Nephrotoxicity, Carcinogenicity, and Underlying Mechanisms. Front Pharmacol. 2019;10:648.

19. Arsenic and Cancer Risk. IARC. May 1, 2019. Retrieved from

https://www.cancer.org/cancer/cancer-

causes/arsenic.html (cited on October 17, 2021)

20. Dixon S. Asbestos Cancer. Retrieved from https://www.asbestos.com/cancer/ (cited on October 17, 2021)

21. Pasternak B, Svanström H, Schmiegelow K, et al. Use of Azathioprine and the Risk of Cancer in
Inflammatory Bowel Disease. Am $J$ Epidemiol. 2013;177(11):1296-1305.

22. Inman GJ, Wang J, Nagano A, et al. The genomic landscape of cutaneous SCC reveals drivers and a novel azathioprine associated mutational signature. Nat Commun. 2018;9:1.

23. Benzene. National Cancer Institute. January 14, $2019 . \quad$ Retrieved from https://www.cancer.gov/about-cancer/causesprevention/risk/substances/benzene (cited on October 17, 2021)

24. McHale CM, Zhang L, Smith MT. Current understanding of the mechanism of benzeneinduced leukemia in humans: implications for risk assessment. Carcinogenesis. 2012;33(2):240-252.

25. Benzidine. National Cancer Institute. January 31, 2019. Retrieved from https://www.cancer.gov/about-cancer/causesprevention/risk/substances/benzidine (cited on October 17, 2021)

26. Tomioka K, Saeki K, Obayashi K, Kurumatani N. Risk of Lung Cancer in Workers Exposed to Benzidine and/or Beta-Naphthylamine: A Systematic Review and Meta-Analysis. $J$ Epidemiol. 2016;26(9):447-458.

27. Beryllium. National Cancer Institute. January 31, 2019. Retrieved from https://www.cancer.gov/about-cancer/causesprevention/risk/substances/beryllium (cited on October 17, 2021)

28. IARC Working Group on the Evaluation of Carcinogenic Risk to Humans. Chemical Agents and Related Occupations. Lyon (FR): International Agency for Research on Cancer; 2012. (IARC Monographs on the Evaluation of Carcinogenic Risks to Humans, No. 100F.) 


\section{BIS(CHLOROMETHYL) ETHER AND} CHLOROMETHYL METHYL ETHER. Available at

https://www.ncbi.nlm.nih.gov/books/NBK304419/

29. 1,3-Butadiene. National Cancer Institute. January 31, 2019. Retrieved from https://www.cancer.gov/about-cancer/causesprevention/risk/substances/butadiene (cited on October 17, 2021)

30. IARC Working Group on the Evaluation of Carcinogenic Risk to Humans. Pharmaceuticals. Lyon (FR): International Agency for Research on Cancer; 2012. (IARC Monographs on the Evaluation of Carcinogenic Risks to Humans, No. 100A.) BUSULFAN. Available at https://www.ncbi.nlm.nih.gov/books/NBK304325/

31. Cadmium. National Cancer Institute. February 1, 2019. Retrieved from https://www.cancer.gov/about-cancer/causesprevention/risk/substances/cadmium (cited on October 17, 2021)

32. Hartwig A. Cadmium and cancer. Met Ions Life Sci. 2013;11:491-507.

33. Chlorambucil. Report on Carcinogens, Fourteenth Edition. National Toxicology Program, Department of Health and Human Services.

34. Semustine. PubChem. Retrieved from https://pubchem.ncbi.nlm.nih.gov/compound/methy 1-CCNU\#section=Chemical-Vendors (cited on October 17, 2021)

35. Chromium Hexavalent Compounds. National Cancer Institute. February 15, 2019. Retrieved from https://www.cancer.gov/about-cancer/causesprevention/risk/substances/chromium (cited on October 17, 2021)
36. Coal Tar and Coal-Tar Pitch. National Cancer Institute. December 28, 2018. Retrieved from https://www.cancer.gov/about-cancer/causesprevention/risk/substances/coal-tar (cited on October 17, 2021)

37. Coke Oven Emissions. National Cancer Institute. February 1, 2019. Retrieved from https://www.cancer.gov/about-cancer/causesprevention/risk/substances/coke-oven (cited on October 17, 2021)

38. IARC Working Group on the Evaluation of Carcinogenic Risk to Humans. Pharmaceuticals. Lyon (FR): International Agency for Research on Cancer; 2012. (IARC Monographs on the Evaluation of Carcinogenic Risks to Humans, No. 100A.) CYCLOPHOSPHAMIDE. Available at https://www.ncbi.nlm.nih.gov/books/NBK304336/

39. Cyclosporin A. Report on Carcinogens, Fourteenth Edition. National Toxicology Program, Department of Health and Human Services.

40. OncoLink Team. Diethylstilbestrol (DES) Exposure. March 12, 2018. Retrieved from https://www.oncolink.org/risk-andprevention/medications-health-history-and-cancerrisk/diethylstilbestrol-des-exposure (cited on October 17, 2021)

41. Epstein-Barr Virus and Cancer. Annu Rev Pathol. 2019;14:29-53.

42. Does EBV cause cancer? Cancer Research UK. May 29, 2019. Retrieved from https://www.cancerresearchuk.org/aboutcancer/causes-of-cancer/infections-eg-hpv-andcancer/does-ebv-cause-cancer (cited on October 17, 2021) 
43. Erionite. National Cancer Institute. February 13, $2019 . \quad$ Retrieved from https://www.cancer.gov/about-cancer/causesprevention/risk/substances/erionite (cited on October 17, 2021)

44. Perkins MS, Toit RL, Africander D. Hormone therapy and breast cancer: emerging steroid receptor mechanisms. $J$ Mol Endocrinol. 2018;61(4):R133-R160.

45. Ethylene Oxide. National Cancer Institute. December 28, 2018. Retrieved from https://www.cancer.gov/about-cancer/causesprevention/risk/substances/ethylene-oxide (cited on October 17, 2021)

46. Formaldehyde. National Cancer Institute. February 14, 2019. Retrieved from https://www.cancer.gov/about-cancer/causesprevention/risk/substances/formaldehyde (cited on October 17, 2021)

47. Does H. pylori cause cancer? Cancer Research UK. May 29, 2019. Retrieved from https://www.cancerresearchuk.org/aboutcancer/causes-of-cancer/infections-eg-hpv-andcancer/does-hpylori-cause-cancer (cited on October 17, 2021)

48. Yang P, Markowitz GJ, Wang XF. The hepatitis B virus-associated tumor microenvironment in hepatocellular carcinoma. Natl Sci Rev. 2014;1(3):396-412.

49. Yi Z, Yuan Z. Hepatitis C Virus-Associated Cancers. Adv Exp Med Biol. 2017;1018:129-146.

50. Does HIV cause cancer? Cancer Research UK. May 29, 2019. Retrieved from https://www.cancerresearchuk.org/aboutcancer/causes-of-cancer/infections-eg-hpv-and- cancer/does-hiv-cause-cancer (cited on October 17, 2021)

51. HPV and Cancer. National Cancer Institute. October 8, 2019. Retrieved from https://www.cancer.gov/about-cancer/causesprevention/risk/infectious-agents/hpv-and-cancer (cited on October 17, 2021)

52. Tagaya Y, Gallo RC. The Exceptional Oncogenicity of HTLV-1. Front Microbiol. 2017;8:1425.

53. Sunil M, Reid E, Lechowicz MJ. Update on HHV-8-Associated Malignancies. Curr Infect Dis Rep. 2010;12(2):147-154.

54. IARC Working Group on the Evaluation of Carcinogenic Risk to Humans. Pharmaceuticals. Lyon (FR): International Agency for Research on Cancer; 2012. (IARC Monographs on the Evaluation of Carcinogenic Risks to Humans, No. 100A.) MELPHALAN. Available at https://www.ncbi.nlm.nih.gov/books/NBK304320/

55. DeCaprio JA. Merkel cell polyomavirus and Merkel cell carcinoma. Philos Trans R Soc Lond B Biol Sci. 2017;372(1732):20160276.

56. IARC Working Group on the Evaluation of Carcinogenic Risk to Humans. Pharmaceuticals. Lyon (FR): International Agency for Research on Cancer; 2012. (IARC Monographs on the Evaluation of Carcinogenic Risks to Humans, No. 100A.) METHOXSALEN PLUS ULTRAVIOLET A RADIATION. Available at https://www.ncbi.nlm.nih.gov/books/NBK304315/

57. Mineral Oils: Untreated and Mildly Treated. National Cancer Institute. February 15, 2019. Retrieved from https://www.cancer.gov/about- 
cancer/causes-prevention/risk/substances/mineraloils (cited on October 17, 2021)

58. Hosseini-khalili A, Haines DD, Modirian E, et al. Mustard gas exposure and carcinogenesis of lung. Mutat Res. 2009;678(1):1-6.

59. IARC Working Group on the Evaluation of Carcinogenic Risk to Humans. Chemical Agents and Related Occupations. Lyon (FR): International Agency for Research on Cancer; 2012. (IARC Monographs on the Evaluation of Carcinogenic Risks to Humans, No. 100F.) 2NAPHTHYLAMINE. Available at https://www.ncbi.nlm.nih.gov/books/NBK304406/

60. Shuryak I, Brenner DJ, Ullrich RL. Radiationinduced carcinogenesis: mechanistically based differences between gamma-rays and neutrons, and interactions with DMBA. PLoS One. 2011;6(12):e28559.

61. Nickel Compounds. National Cancer Institute. February 15, 2019. Retrieved from https://www.cancer.gov/about-cancer/causesprevention/risk/substances/nickel (cited on October 17, 2021)

62. Radon. National Cancer Institute. February 20, 2019. Retrieved from https://www.cancer.gov/about-cancer/causesprevention/risk/substances/radon (cited on October 17, 2021)

63. Crystalline Silica. National Cancer Institute. February 1, 2019. Retrieved from https://www.cancer.gov/about-cancer/causesprevention/risk/substances/crystalline-silica (cited on October 17, 2021)

64. Moan J, Dahlback A, Lagunova Z, Cicarma E, Porojnicu AC. Solar Radiation, Vitamin D and
Cancer Incidence and Mortality in Norway. Anticancer Res. 2009;29(9):3501-3509.

65. Soot. National Cancer Institute. February 20, 2019. Retrieved from https://www.cancer.gov/about-cancer/causesprevention/risk/substances/soot (cited on October 17, 2021)

66. Strong Inorganic Acid Mists Containing Sulfuric Acid. National Cancer Institute. February 20, 2019. Retrieved from https://www.cancer.gov/about-cancer/causesprevention/risk/substances/inorganic-acid (cited on October 17, 2021)

67. Fears TR, Sagebiel RW, Halpern A, et al. Sunbeds and sunlamps: who used them and their risk for melanoma. Pigment Cell Melanoma Res. 2011;24(3):574-581.

68. Phillips DH. Understanding the genotoxicity of tamoxifen? Carcinogenesis. 2001;22(6):839-849.

69. $\mathrm{Xu} \mathrm{J}, \mathrm{Ye} \mathrm{Y,} \mathrm{Huang} \mathrm{F,} \mathrm{et} \mathrm{al.} \mathrm{Association}$ between dioxin and cancer incidence and mortality: a meta-analysis [published correction appears in Sci Rep. 2017 Feb 10;7:41665]. Sci Rep. 2016;6:38012.

70. Thiotepa. Report on Carcinogens, Fourteenth Edition. National Toxicology Program, Department of Health and Human Services.

71. Thorium. National Cancer Institute. February 20, 2019. Retrieved from https://www.cancer.gov/about-cancer/causesprevention/risk/substances/thorium (cited on October 17, 2021)

72. Tobacco. National Cancer Institute. January 23, 2017. Retrieved from 
https://www.cancer.gov/about-cancer/causes-

prevention/risk/tobacco (cited on October 17, 2021)

73. Carreón T, Hein MJ, Hanley KW, et al. Bladder cancer incidence among workers exposed to otoluidine, aniline and nitrobenzene at a rubber chemical manufacturing plant. Occup Environ Med. 2014;71(3):175-182.

74. Trichloroethylene (TCE). National Cancer Institute. December 10, 2018. Retrieved from https://www.cancer.gov/about-cancer/causesprevention/risk/substances/trichloroethylene (cited on October 17, 2021)

75. Vinyl Chloride. National Cancer Institute. December 28, 2018. Retrieved from https://www.cancer.gov/about-cancer/causesprevention/risk/substances/vinyl-chloride (cited on October 17, 2021)

76. Wood Dust. National Cancer Institute. December 28, 2018. Retrieved from https://www.cancer.gov/about-cancer/causesprevention/risk/substances/wood-dust (cited on October 17, 2021)

77. Do x-rays and gamma rays cause cancer? American Cancer Society. February 24, 2015. Retrieved from https://www.cancer.org/cancer/cancercauses/radiation-exposure/x-rays-gamma-rays/doxrays-and-gamma-rays-cause-cancer.html (cited on October 17, 2021)

78. Knudson AG Jr. Mutation and cancer: statistical study of retinoblastoma. Proc Natl Acad Sci USA. $1971 ; 68: 820-3$. 